\title{
Spherical Explosions and the Equation of State of Water
}

\author{
D. J. Steinberg
}

\section{DO NOT MICROFILM COVER}

February 1987

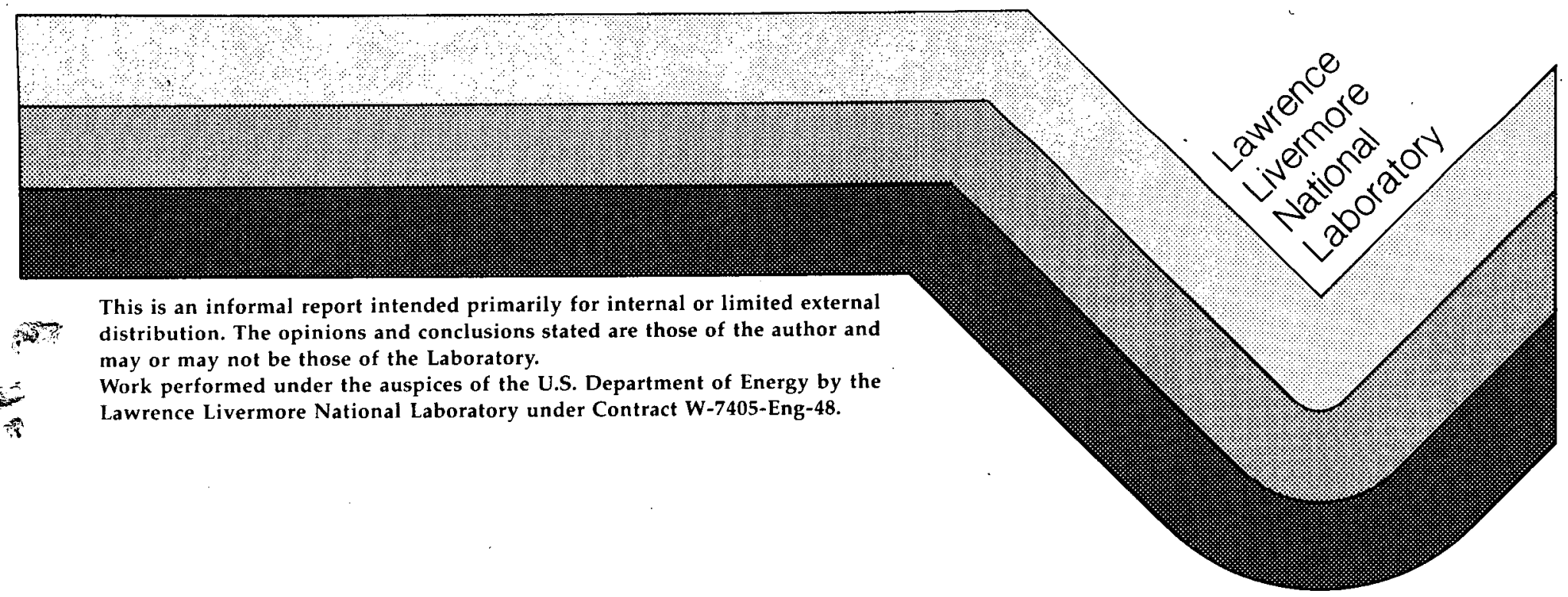

DISTRIBUTION OF THIS DOCUMEUT IS UNLIMITED 


\section{DISCLAIMER}

This report was prepared as an account of work sponsored by an agency of the United States Government. Neither the United States Government nor any agency Thereof, nor any of their employees, makes any warranty, express or implied, or assumes any legal liability or responsibility for the accuracy, completeness, or usefulness of any information, apparatus, product, or process disclosed, or represents that its use would not infringe privately owned rights. Reference herein to any specific commercial product, process, or service by trade name, trademark, manufacturer, or otherwise does not necessarily constitute or imply its endorsement, recommendation, or favoring by the United States Government or any agency thereof. The views and opinions of authors expressed herein do not necessarily state or reflect those of the United States Government or any agency thereof. 


\section{DISCLAIMER}

Portions of this document may be illegible in electronic image products. Images are produced from the best available original document. 
UCID--20974

DE87 006587

\title{
Spherical Explosions and the Equation of State of Water
}

\author{
D. J. Steinberg
}

February 1987

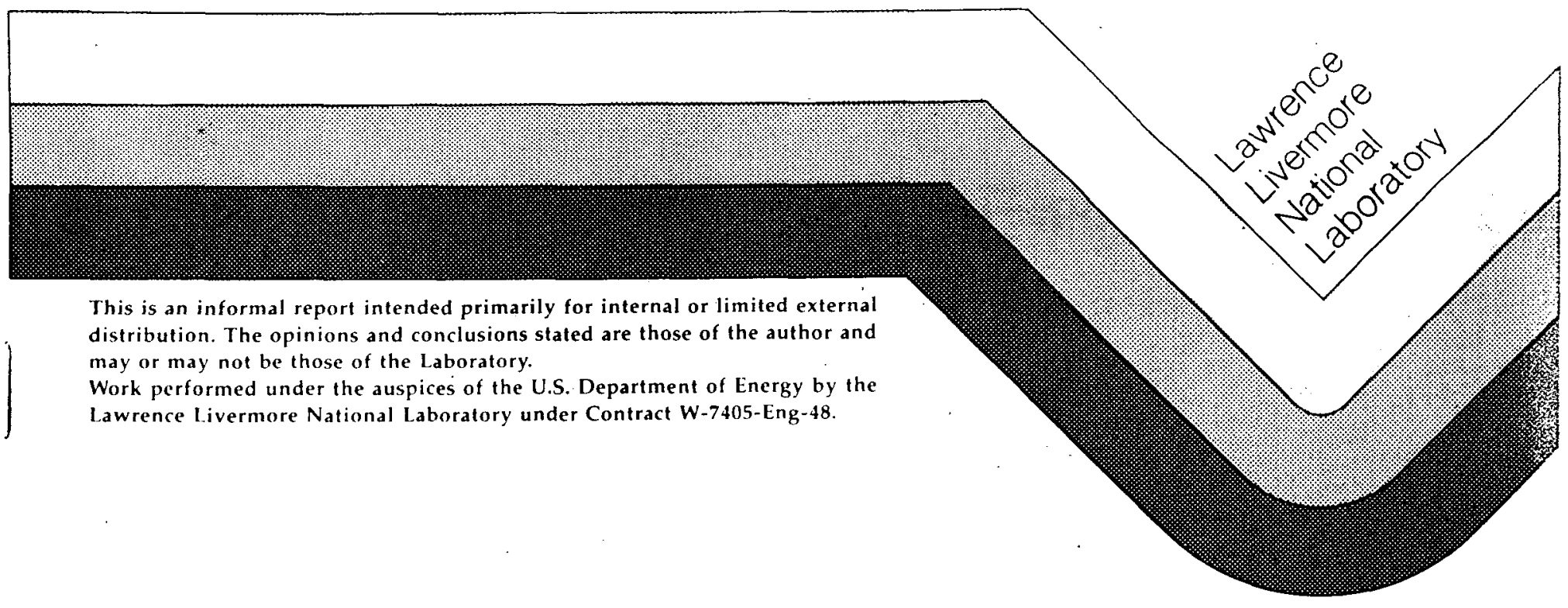

DISTRIBUTION OF THIS DOCUREIT IS UNLIMITED 


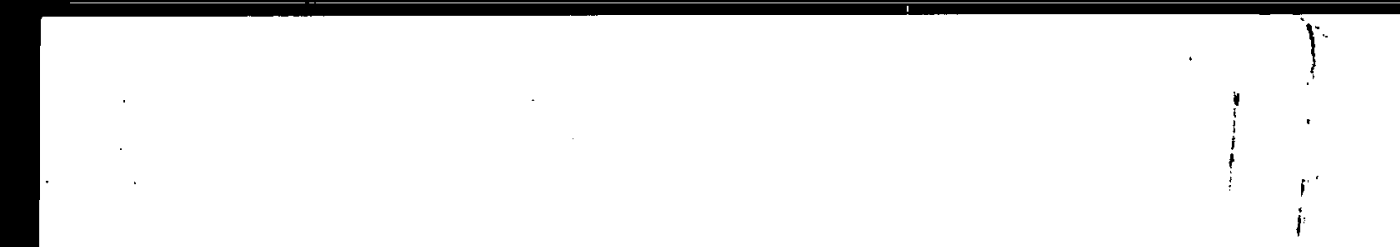




\title{
Spherical Explosions and the Equation of State of Water
}

\begin{abstract}
We have successfully calculated an experiment in which a sphere of detonated nitromethane expands into water. The calculations are sensitive to both the nitromethane and water equations of state. For water, the most important aspect of the equation of state is the Hugoniot.
\end{abstract}

\section{Introduction}

The equation of state (EOS) of water plays an important role in calculating the damage caused by the collapse of large bubbles against submarine hulls. One potentially useful experiment regarding the EOS of water was performed by Helm et al. and consisted of a $76.2 \pm 0.254-\mathrm{mm}$-radius sphere of nitromethane (NM) contained in an 1100-O Al sphere of nominal thickness of $3.175 \mathrm{~mm} .{ }^{1}$ The sphere was centered in a 3-m-diam water bath, $1.8 \mathrm{~m}$ from the top of the water and $1.2 \mathrm{~m}$ from the bottom. The mass of NM was approximately $2.1 \mathrm{~kg}$.

In operation, the NM is detonated at its center and the detonation products then expand the $\mathrm{Al}$ sphere. The diagnostics used to follow the ex- pansion were a specially modified model 75 streak camera and, for backup, two Hycam framing cameras-one operating at $100-\mu$ s interframe time, the other at $50 \mu \mathrm{s}$. The bottom of the pool was lined with light-reflecting material and three highintensity xenon flash lamps on top of the water provided the light source.

The experiment, as originally conceived, was to diagnose the late-time or low-pressure expansion of NM. This approach assumed the EOS of water was well known. Our purpose is to reevaluate the experiment, and by assuming the EOS of $\mathrm{NM}$ as known, to see what effect the water EOS has on the system.

\section{Experimental Data}

Primary data are the bubble radius time record from the streak camera. This record lasts about $920 \mu \mathrm{s}$ and can be divided into two parts. For the first $80 \mu \mathrm{s}$, the water behind the shock wave is compressed enough that it has an index of refraction $n$ significantly different from the uncompressed water ahead of the shock. This change in $n$, coupled with the small radius of curvature of the shock, causes the shocked water to act as a lens, making the image of the bubble larger than the actual bubble. This magnification must be accounted for to compare the experiment with calculation. Beyond $80 \mu \mathrm{s}$, the magnification is sufficiently small that the data and calculation can be compared directly. The streak-camera record also shows a disturbance that is definitely related to the movement of the shock wave through the water.

The streak data have several sources of error. These are principally reading errors, the initial ra- dius of the $\mathrm{Al}$ shell, and the total optical system magnification. The first can be a random or absolute error, the second two, absolute only.

Frank Helm supplied several readings of the streak-camera data. ${ }^{2}$ Differences of as much as $1.2 \mathrm{~mm}$ existed, but typically the readings were within $\pm 0.5 \mathrm{~mm}$, with the average difference being $0.15 \mathrm{~mm}$. There was no discernible trend in these differences with increasing radius. Assuming the error for the outside radius of the shell to be the same as for the inside, we estimate the initial radius to be known to $\pm 0.5 \mathrm{~mm}$.

The total system magnification was determined by placing a $145-\mathrm{mm}$-long scale at the same position as the $\mathrm{Al}$ sphere. The set-up picture at the streak camera could then be used to measure the magnification directly. The water was sufficiently cloudy that it was impossible to see clearly the markings on the scale, so only the total length was used. We estimate that this length can 
be measured, at best, to $\pm 0.05 \mathrm{~mm}$ or $\pm 0.35 \%$. At the maximum expansion of about $220 \mathrm{~mm}$, this implies an uncertainty of $\pm 0.8 \mathrm{~mm}$. The magnification factor was determined to be 0.1135 .

Supplementing the streak-camera data and extending the experimental record to $1250 \mu \mathrm{s}$, are results from the two framing cameras. The best of these records, and the most consistent with the streak data, is from the $50-\mu \mathrm{s}$ interframe-time camera that recorded to only $1210 \mu \mathrm{s}$. These data are more difficult to analyze than the streak record; the edges are fuzzier and the pictures not always perfectly circular. Frank Helm also supplied his version of the reduced data. ${ }^{2}$ Using a magnification factor of 0.1135 , the Hycam results were about $0.9 \%$ higher than the streak data. Considering the other uncertainties in the experiment, we chose not to pursue this discrepancy further. The streak and framing camera data are compared in Fig. 1.

\section{Determining the Index-of-Refraction Correction}

'To determine the index-of-refraction correction, we first calculated density profiles in the shocked water at a series of times. These profiles showed that the density could be well represented by a linear ramp. Fortunately, when the profiles became nonlinear, the corrections were very small. The index of refraction was then computed from the Gladstone-Dale formula, which is linear in the density. Hence, we assumed that $n$ varies linearly through the shocked water. The only additional information required was the calculated radii of the bubble and shock front as functions of time. Charles McMillan of Lawrence Livermore National Laboratory wrote a simple ray-tracing

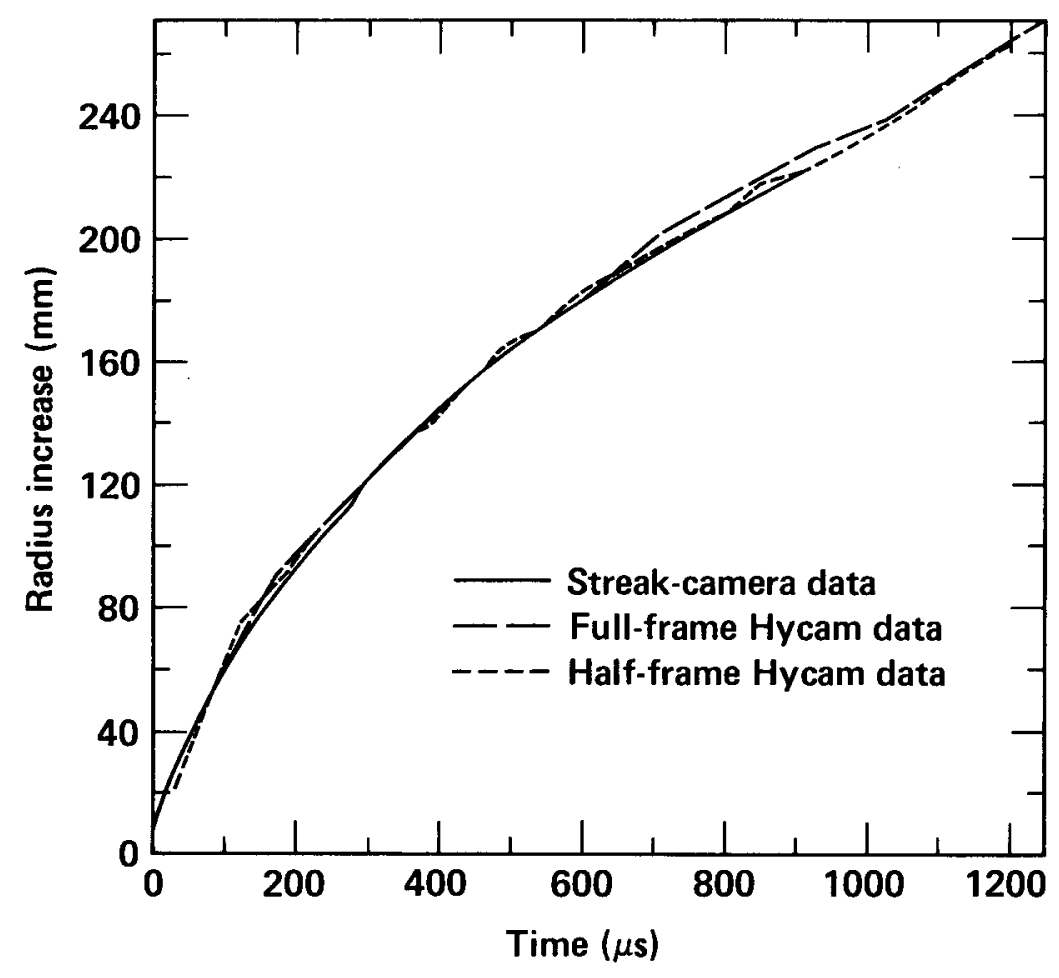

Figure 1. Comparison of streak and framing camera data for the underwater detonation of nitromethane contained in an aluminum sphere. Framing camera results have been lowered $0.9 \%$ to normalize them to streak-camera data. 
code that used all the above parameters to calculate the apparent increase in the bubble radius. ${ }^{3}$

In the course of computing these corrections, we noted that the density at the bubble-water interface plays the dominant role in determining the size of the correction. The density at the shock front is relatively unimportant for the following reason. If we assume a constant index through the water, then a ray tangent to the bubble will be bent by an angle $\theta_{1}$ as it enters the unshocked water. If this same ray moves through water with a steadily increasing index, then it will be bent away from the bubble. However, because of the higher index now at the shock front, the ray will be bent back toward the bubble by an angle $\theta_{2}>$ $\theta_{1}$ when it enters the unshocked water. The increase in bending angle $\theta$ cancels out, to first order, the initial bending in the other direction in the shocked water.

In addition, it was noted that even for the smallest bubble radius, putting the radius of curvature of the shock front at infinity only changed the magnification by $\sim 10 \%$. Therefore, it is reasonable to say that the magnification $M$ due to the change of index of refraction can be approximated quite well by the simple relationship $M=n_{2} / n_{1}$, where $n_{2}$ is the index at the bubble-water interface and $n_{1}$ is the index (1.333) in the unshocked water.

\section{Equations of State Used in the Calculations}

The NM EOS is a standard JWL EOS, ${ }^{4}$ and we constructed the $\mathrm{Al} \mathrm{EOS,} \mathrm{including} \mathrm{the} \mathrm{constitutive}$ model. The principal water EOS is in the Gruneisen form. The Hugoniot data from Refs. 5-7 were combined and fit using the nonlinear $u_{\mathrm{s}}-u_{\mathrm{p}}$ form in Eq. (1).

$$
\begin{aligned}
& u_{\mathrm{s}}=0.148+2.56 u_{\mathrm{p}}-1.986\left(\frac{u_{\mathrm{p}}}{u_{\mathrm{s}}}\right) u_{\mathrm{p}} \\
& +0.2268\left(\frac{u_{\mathrm{p}}}{u_{\mathrm{s}}}\right)^{2} u_{\mathrm{p}} .
\end{aligned}
$$

Gamma $(\gamma)$ was taken from Gurtman et al. ${ }^{8}$ and is described by Eq. (2):

$$
\gamma=\frac{0.5+2.67 \mu}{1+\mu} \text { for } 0<\mu<1
$$

or

$$
\gamma=\frac{0.5}{1+\mu} \text { for } \mu<0 .
$$

Here, $u_{\mathrm{s}}$ and $u_{\mathrm{p}}$ are the shock and particle velocities, respectively, in $\mathrm{cm} / \mu \mathrm{s}$, and $\mu=\rho / \rho_{0}-1$, where $\rho$ is the density of the water and the initial density $\rho_{0}$ is $1 \mathrm{~g} / \mathrm{cm}^{3}$. Subsequent calculations showed that the water Hugoniot was the most important component in this study.

\section{Discussion}

Figure 2 compares the data and a calculation using the Gruneisen EOS described above. All calculations are done with a one-dimensional implicit hydro code, GEM. ${ }^{9}$ Only the Hycam data for $\mathrm{t}>920 \mu \mathrm{s}$ are shown. The initial radius was $79.375 \mathrm{~mm}$ and zero time corresponds to the initial motion of the shell. This time normalization was accomplished using a calculated value of $14.5 \mu \mathrm{s}$ for the shock travel-time through the NM and $\mathrm{Al}$ shell. For $\mathrm{t}>100 \mu \mathrm{s}$, the calculation does not differ from the data by more than $3.5 \mathrm{~mm}$ or $2 \%$.

Figure 3 compares data and calculation for the first $100 \mu \mathrm{s}$. The calculation, corrected for the index-of-refraction effect, is also shown and it agrees well with the data. For the first $40 \mu \mathrm{s}$, the corrected calculation is consistently high by $0.7 \mathrm{~mm}$. The most likely explanation is that the calculated density distribution used to make the correction may not accurately reflect reality.

It is impossible to correct the first few microseconds of calculation. Because of internal reflection, the bubble is not visible experimentally for the first $2 \mu \mathrm{s}$; calculationally, the value was about $3.5 \mu \mathrm{s}$. As for the abrupt changes in the data at $\mathrm{t} \sim 40$ and $80 \mu \mathrm{s}$, we can offer no explanation. Figure 4 shows the differences over time, in millimeters and percent, between calculation and experiment for a combination of Figs. 2 and 3. 


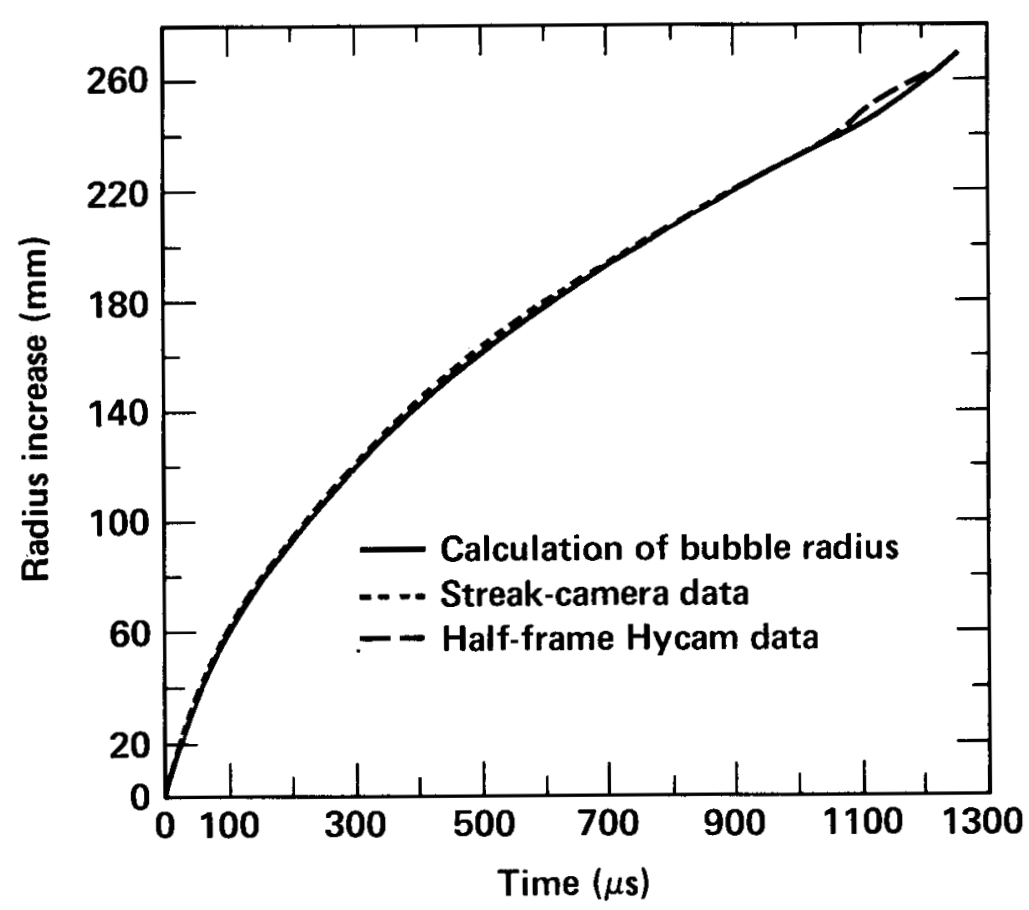

Figure 2. Comparison of calculated, bubble radius-time with experimental data. Only the framing camera results for $t>920 \mu$ s are shown.

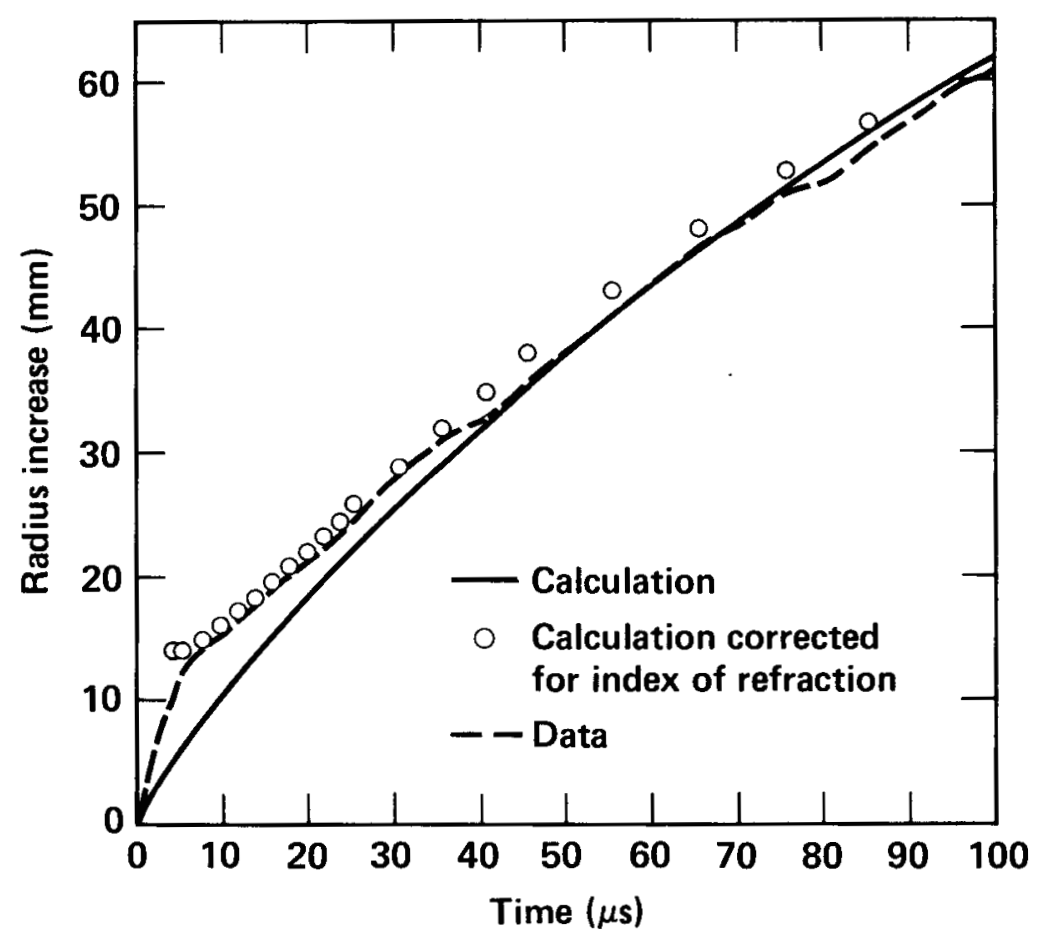

Figure 3. Bubble radius-time for the first $100 \mu \mathrm{s}$. Shown are the data, the hydrodynamic calculation, and the calculation corrected for the index of refraction of the water. 


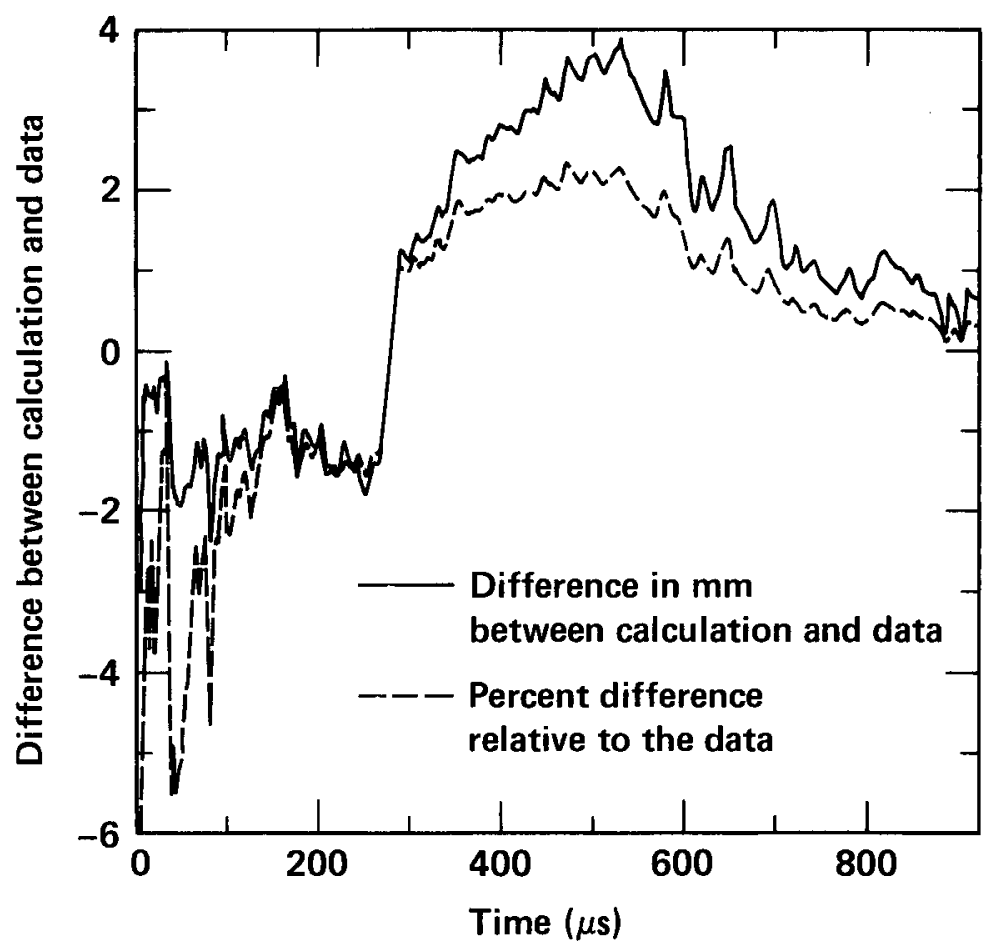

Figure 4. Differences, in millimeters and percent, between experiment and index-of-refraction corrected calculations.

Helm's data also show some optical disturbance that is related to the passage of the shock wave. This disturbance is presumably caused by the changing index of refraction, that is, changing density, of the water. Figure 5 compares the data with a calculation of the maximum density in the shocked water. The agreement in shape is very good, but on the average the data are about $10 \mathrm{~mm}$ behind the point of maximum density. Because this experiment was not designed to measure shock position, and it is not clear what is actually being measured, we have not pursued this matter further. Figure 6 is helpful to show the shock wave vis-à-vis the bubble position.

The boundaries of the experiment can affect the results. This is illustrated in Fig. 7. The outside of the NM sphere is $112 \mathrm{~cm}$ from the bottom of the water tank, but $142 \mathrm{~cm}$ from the side walls. Therefore, a two-dimensional calculation is required to do a proper comparison with the experiment. However, we can get some effect of the boundaries by comparing the calculations with the free-surface 112 and $142 \mathrm{~cm}$ away. The data imply that when the shock wave hits the bottom it may be phasing out radially and eventually affecting the streak record. Hence, the calculation with the boundary at $112 \mathrm{~cm}$ may be more representative of the experiment than the one where the boundary is $142 \mathrm{~cm}$ away. However, since the upward curvature of the data is seen only in the last two frames, it is difficult to reach any definite conclusion.

Calculations were also done with other versions of the water EOS. These included an analytic EOS by Glenn and Young, ${ }^{10}$ and several tabular EOSs based on the work of Ree. ${ }^{11}$ The results are not very sensitive to the choice of EOS; in particular, the decompressed region does not play a major role. The most important part of the EOS appears to be the Hugoniot. If Eq. (1) is replaced by a linear $u_{\mathrm{s}}-u_{\mathrm{p}}$ approximation to the data, then a calculation shows the system to be less energetic; the radius of the bubble is now about $2 \mathrm{~mm}$ less at $900 \mu$ s than the baseline calculation shown in Fig. 2. The Glenn and Young EOS also uses the same linear $u_{\mathrm{s}}-u_{\mathrm{p}}$ Hugoniot; at $900 \mu \mathrm{s}$ the radius calculated with this EOS is $3 \mathrm{~mm}$ less.

Calculations done with the tabular EOS show the bubble radius to be only $1 \mathrm{~mm}$ less at $900 \mu \mathrm{s}$ than the baseline calculation. One of these tables includes all the steam table data and other physics. 


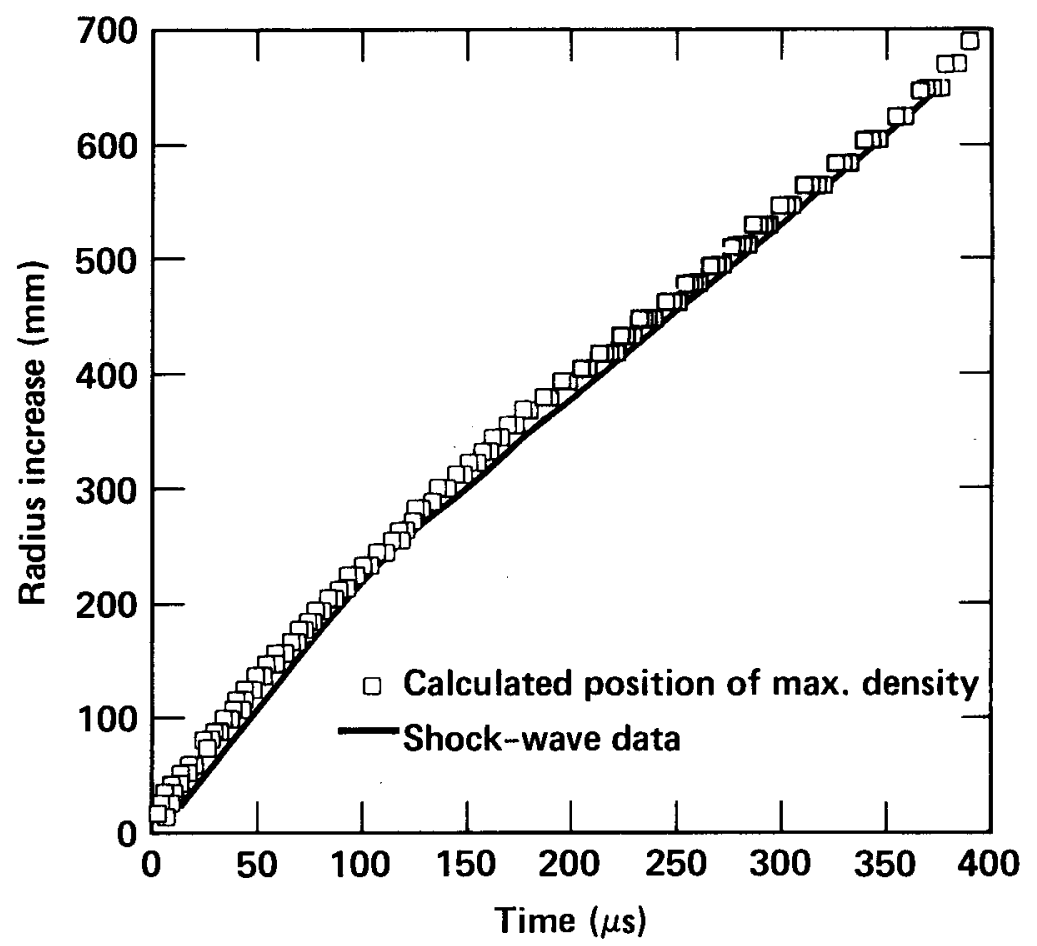

Figure 5. Comparison of shock-wave data with the calculated position of maximum density.

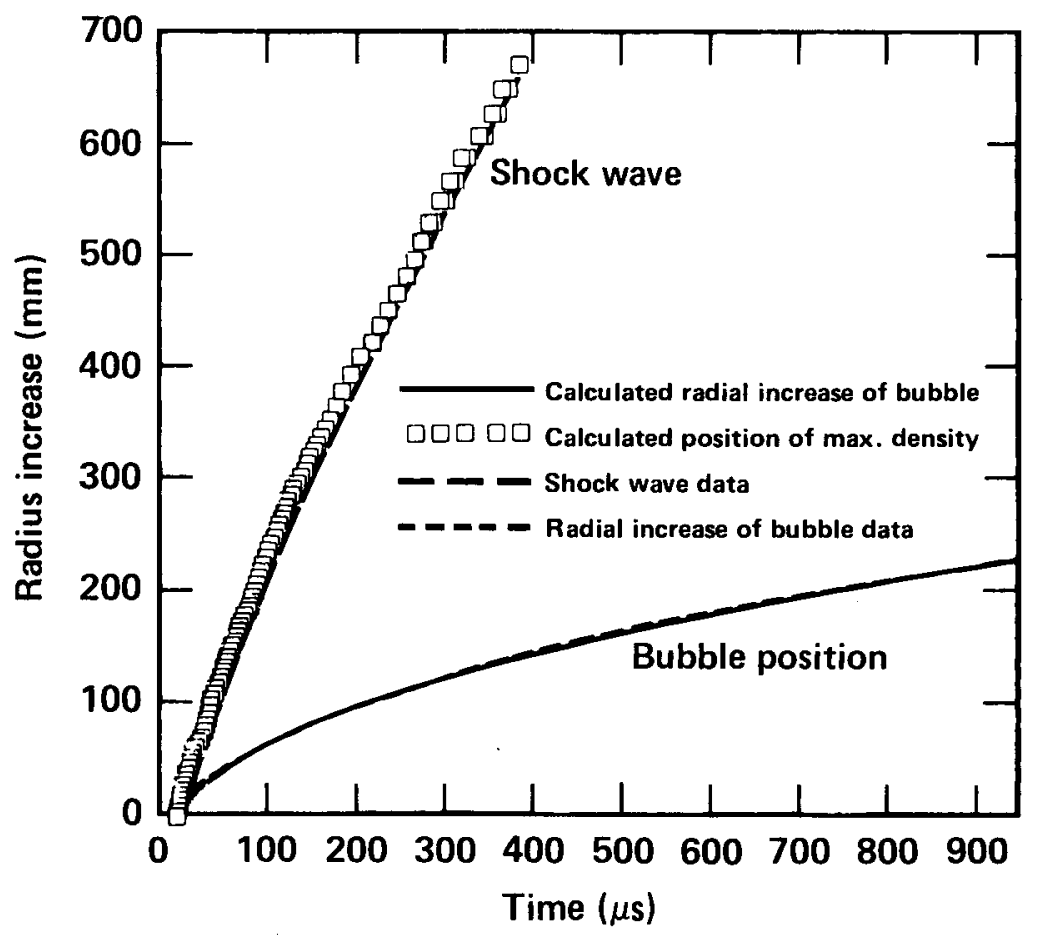

Figure 6. Comparison of both bubble and shock-wave radiustime data and calculation. 


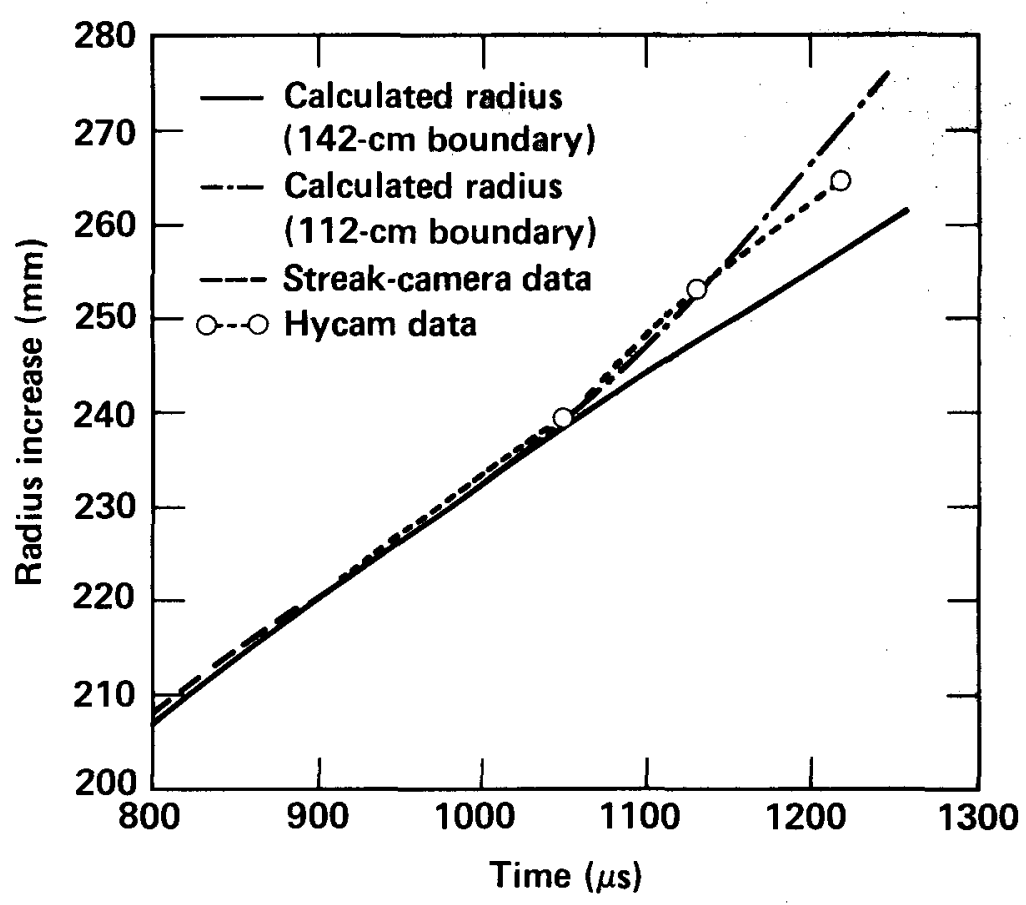

Figure 7. Comparison of calculated bubble radius-time with experimental data assuming different boundary conditions:

Finally, this experiment seems more sensitive to the NM EOS. We increased the detonation energy by only $2 \%$, from 0.051 to $0.052 \mathrm{Mb}-\mathrm{cm}^{3} / \mathrm{cm}_{0}^{3}$, and improved the overall agreement by about 25 to $30 \%$. The detonation energy is not known to $2 \%$ accuracy.

\section{Conclusions}

Water is a well-studied fluid. Therefore, it is not surprising that all water EOSs give about the same results. Except for the region around $500 \mu \mathrm{s}$, the agreement between experiment and calculation is excellent. What differences there are could be attributed to uncertainties in the NM EOS.

\section{Acknowledgments}

Our thanks to Charles McMillan for writing the ray-tracing code, and to Frank Helm for his assistance in locating and interpreting the original data. 


\section{References}

1. F. H. Helm, Jr., E. S. Chambers, E. Lee, M. Finger, R. R. McGuire, J. P. Mahler, H. Cheung, and J. L. Cramer, Detonation-Product Behavior at Large Expansion of the Underwater Detonation of Nitromethane, Lawrence Livermore National Laboratory, Livermore, Calif., UCRL-52903 (1980). This reference has some interesting diagrams and photographs of the experimental setup and raw data, plus a brief description of how the streak camera was modified to run at uniform speeds as slow as $5 \mathrm{rps}$. The rest of the paper, however, contains many inaccuracies and inconsistencies.

2. F. H. Helm, Lawrence Livermore National Laboratory, Livermore, Calif., private communication (1986).

3. C. McMillan, Lawrence Livermore National Laboratory, Livermore, Calif,, private communication (1986).

4. E. Lee, M. Finger, and W. Collins, JWL Equation of State Coefficients for High Explosives, Lawrence Livermore National Laboratory, Livermore, Calif., UCID-16189 (1973).

5. M. Van Thiel, Compendium of Shock Wave Data, Lawrence Livermore National Laboratory, Livermore, Calif., UCRL-50108 (1977), vols. 1-3, rev. 1, p. 333.

6. P. C. Lysne, "A Comparison of Calculated and Measured Low-Stress Hugoniots and Release Adiabats of Dry and Water-Saturated Tuff," J. Geophys. Res. 75, 4375 (1970).

7. G. Bloom, Lawrence Livermore National Laboratory, Livermore, Calif., private communication (1986).

8. G. A. Gurtman, J. W. Kirsch, and C. R. Hastings, "Analytical Equation of State for Water Compressed to 300 Kbar," J. Appl. Phys. 42, 851 (1971).

9. C. Lund, Lawrence Livermore National Laboratory, Livermore, Calif., private communication (1986).

10. L. Glenn and D. Young, Blast Attenuation in a Shot Tunnel Using Water Jets, Lawrence Livermore National Laboratory, Livermore, Calif., UCID-19419 (1982).

11. F. H. Ree, Equation of State of Water, Lawrence Livermore National Laboratory, Livermore, Calif, UCRL-52190 (1976). 